\title{
High Efficiency LSM with High Flux Density for Transportation
}

\author{
Nobuo Fujii ${ }^{1}$, Mitsunobu Terata ${ }^{1}$, Takeshi Mizuma ${ }^{2}$ \\ ${ }^{1}$ Faculty of Information Science and Electrical Engineering, Kyushu University, Fukuoka, Japan \\ ${ }^{2}$ National Traffic Safety \& Environment Laboratory, Tokyo, Japan \\ E-mail: fujii@ees.kyushu-u.ac.jp \\ Received May 17, 2011; revised July 25, 2011; accepted August 27, 2011
}

\begin{abstract}
A new linear synchronous motor (LSM) with permanent magnet (PM) is proposed to develop a linear motor for transportation with high efficiency. The LSM has very high air-gap flux density beyond the remanent magnetization of rare earth PM, which is generated by a special field structure with rare earth PM. Two PMs are arranged to form a triangle over each pole to concentrate the flux of PMs. The maximum value of air-gap flux density is limited to the magnetic saturated value in the core of field and armature, respectively, which is about 2T. The configuration is insusceptible to armature reaction because of large equivalent magnetic resistance in the flux path. The characteristics are analyzed using a two-dimensional finite element method (FEM) considering the core material. For high air-gap flux density and small armature reaction, the very high thrust density beyond the conventional maximum value of $100 \mathrm{kN} / \mathrm{m}^{2}$ can be obtained. Using normal thrust density with small magneto-motive force (mmf) of armature, this LSM has efficiency and power factor that are as high as or higher than a rotational motor.
\end{abstract}

Keywords: Permanent Magnet, Synchronous Motor, Linear Synchronous Motor, LSM, High flux Density, High Efficiency, Linear Motor, Transportation

\section{Introduction}

Various kinds of linear synchronous motors (LSMs) have been designed for new applications [1]. The characteristics of LSM are basically similar to those of rotational synchronous motor (SM). The amplitude of air-gap flux density generated by the field of LSM for transportation is generally not large because of large gap for safety. In the case of low flux density in air-gap, the efficiency is not good because the large magneto-motive force (mmf) of armature winding is needed to obtain the required thrust and it causes the large ohmic loss in a normal conducting coil. It is often used Halbach array [2] to get a large air-gap flux density by using rare earth permanent magnet (PM), whose value is under about $1 \mathrm{~T}$ even in the use of most strong PM.

We contrive a new field for LSM or SM to obtain the higher air-gap flux density than the remanent magnetization of rare earth PM [3]. In the paper, the characteristics of LSM are analyzed by using a finite element method (FEM). The influence of magnetic saturation and armature reaction is investigated respectively. The ripple of thrust and normal force in the running are checked for concentrated three-phase armature winding. The efficiency and power factor are shown respectively.

\section{Proposed PM LSM With High-Flux Density}

The fundamental structure of proposed LSM is shown in Figure 1. This motor is quite different from IPM (interior permanent magnet)-SM in magnetic properties in spite of similar appearance. Two PMs are arranged to form a triangle over each pole to concentrate the flux of PMs. The both ends of PM are set to the surface of air-gap and the backside of magnetic field to be wide as much as possible for the width of PM. The thickness of yoke connected to N-pole and S-pole of field pole are almost equal to the thickness of magnetic field to be hard to the magnetic saturation. On the other hand, in the armature, the three-phase winding is the concentrated winding to be wide as much as possible in the width of tooth and to be hard to the magnetic saturation in the tooth.

The higher air-gap flux density than the remanent 
magnetization of PM can be obtained by choosing the size of length and thickness of PM. The maximum value of air-gap flux density is limited to the magnetic saturated value in the core of field and armature respectively, which is about $2 \mathrm{~T}$.

In the path of flux, the equivalent length of air-gap is very large, which is equal to the summation of gap length and thickness of PM in case of rare earth type. That is, this configuration is insusceptible to armature reaction.

\section{Analytical Model}

An example model is shown in Table 1. The pole pitch is $0.24 \mathrm{~m}$, and the air-gap or the mechanical clearance between the magnetic pole and the armature is $12 \mathrm{~mm}$, which is equal to that of linear-motor-subway in Tokyo.

The remanent magnetization of rare earth type PM is 1.15T. By using FEM tool named JMAG made in Japan, two-dimensional analysis is performed in consideration of magnetic saturation of core, in which the periodic boundary condition in the longitudinal direction is used for one pole pair. In the armature, the winding is three-phase concentrated winding in relatively deep slot to be wide width of tooth as a countermeasure for magnetic saturation. The slot is a simple open slot as an immediate measure.

\section{Characteristics}

\subsection{Flux Distribution}

Figure 2 and Figure 3 show the flux distribution of the numerical example of Table I. For a smooth core armature, the air-gap flux density on the magnetic pole is $1.32 \mathrm{~T}$ and it is uniform. The curves in Figure 2(a) and 3(a) are the distributions at middle of air-gap. The dashed line in Figure 2(a) represents the distribution for

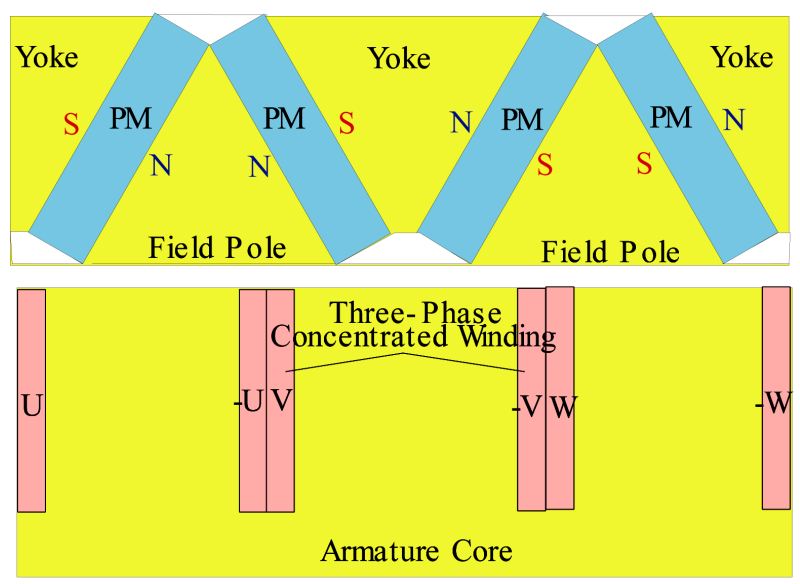

Figure 1. PM LSM with high air-gap flux density.
Table 1. Parameters of proposed LSM model.

\begin{tabular}{ll}
\hline \multicolumn{2}{c}{ Magnetic Field } \\
\hline Pole pitch & $0.240 \mathrm{~m}$ \\
Length of field pole & $0.160 \mathrm{~m}$ \\
Coercive force of PM & $915 \mathrm{kA} / \mathrm{m}$ \\
Remanent magnetization of PM & $1.15 \mathrm{~T}$ \\
Thickness of PM & $0.040 \mathrm{~m}$ \\
Thickness of yoke & $0.113 \mathrm{~m}$ \\
Material of field core & $\mathrm{JFE} 50 \mathrm{JN} 800$ \\
Mechanical clearance & $0.012 \mathrm{~m}$ \\
& \\
Rated current density of winding & $4.5 \mathrm{~A} / \mathrm{mm}{ }^{2}$ \\
Width of slot & $0.050 \mathrm{~m}$ \\
Depth of slot & $0.150 \mathrm{~m}$ \\
Thickness of yoke & $0.055 \mathrm{~m}$ \\
Width of core & $0.200 \mathrm{~m}$ \\
Material of armature core & $\mathrm{JFE} 50 \mathrm{JN} 800$ \\
\hline
\end{tabular}

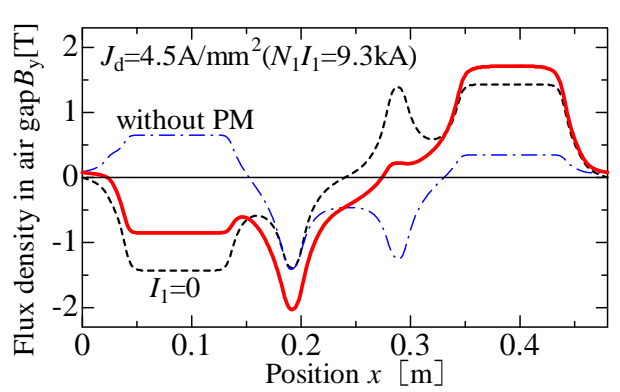

(a)

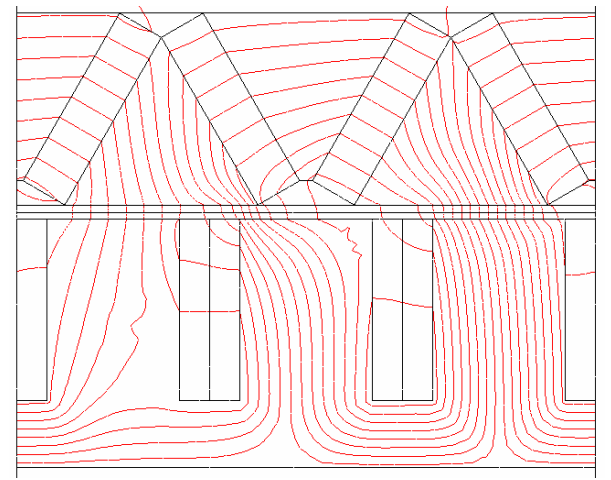

(b)

Figure 2. Flux distribution at position with maximum thrust. (a) Flux density distribution in airgap; (b) Line of magnetic force.

the armature core with slot and without current. The distribution is symmetric with respect to the central axis of $\mathrm{N}$ and $\mathrm{S}$ magnetic poles. As the flux concentrates at the tooth of armature, the flux density in both sides of teeth of armature increases to $1.44 \mathrm{~T}$. The dot-dashed line represents the flux density produced only by armature 
winding at the rated current, whose phase is adjusted to obtain the maximum thrust in this spatial arrangement. The bold solid line represents the distribution of LSM. Figure 2(b) shows the corresponding magnetic flux lines of solid line in Figure 2(a). The flux density in the yoke of field is not high in this structure. The magnetic saturation occurs only in the small overlap region between the field pole and the tooth of armature.

The flux distribution at different positional relation between the field and the armature is shown in Figure 3. The thrust at the position is minimum in variation of thrust.

\subsection{Force Characteristics}

The thrust, which corresponds to the torque in the rotational motor, is varied for the phase of armature current and the spatial relation between the field and the armature. The optimum phase for maximum thrust is defined as $\varphi_{o}$ in the case shown in Figure 2. When the mmf of armature winding is varied, the optimum phase is defined to be $\varphi_{o}+\Delta \varphi_{o}$ here. Figure 4 shows the phase. In the following thrust and normal force, the phase in Figure 4 is used.

The thrust of one-pole-pair length as functions of mmf of armature winding is shown in Figure 5. When the thrust density is defined as the thrust per the area of airgap region, $9.6 \mathrm{kN}$ corresponds to the thrust density

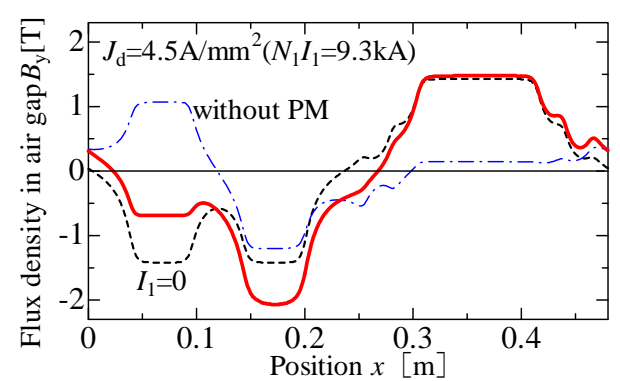

(a)

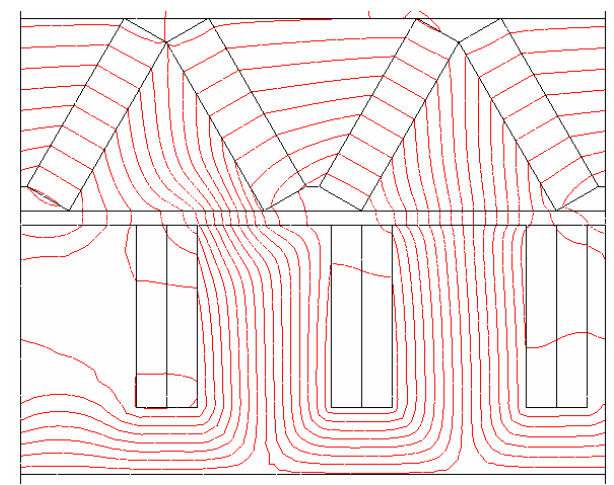

(b)

Figure 3. Flux distribution at different position. (a) Flux density distribution in airgap; (b) Line of magnetic force. of $100 \mathrm{kN} / \mathrm{m}^{2}$, which is about the highest value in all type of motors included rotational motor. The value of $100 \mathrm{kN} / \mathrm{m}^{2}$ is achieved by HD motor [4], which is a type of stepping motor using PM with very small air-gap. In Figure 5, the influence of magnetic saturation as increase of armature mmf is very small. This LSM can generate larger thrust easily by increasing the armature mmf considering the current density, which is adjusted by the depth of slot.

Figure 6 shows the ripple of thrust. The rate of ripple for average is within $\pm 5.4 \%$, which is not large. Although the thrust ripple in application of transportation is not a serious problem because of very large inertia, the ripple will decrease by a design of slot shape if necessary.

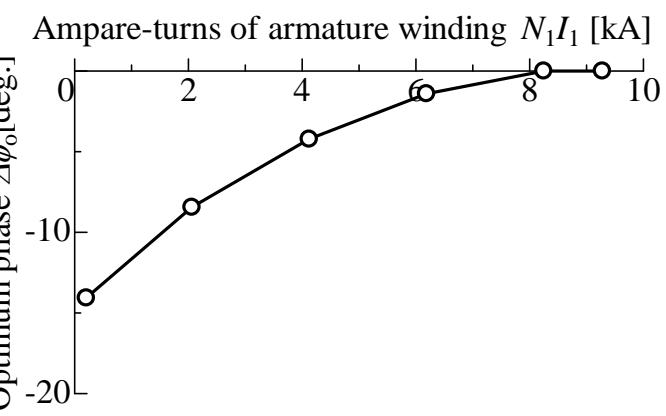

Figure 4. Phase for maximum thrust.

Current density of armature winding $J_{\mathrm{d}}\left[\mathrm{A} / \mathrm{mm}^{2}\right]$

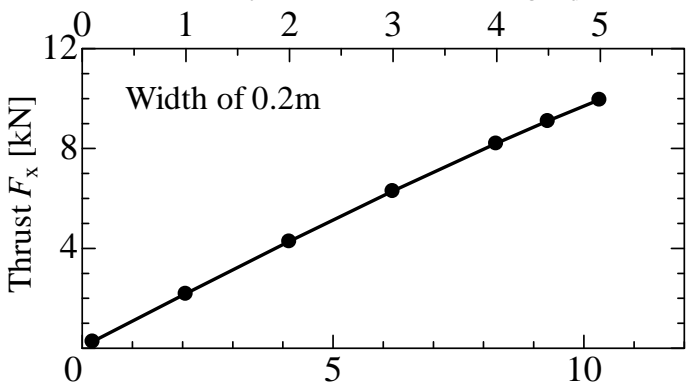

Ampare-turns of armature winding $N_{1} I_{1}[\mathrm{kA}]$

Figure 5. Thrust curve as functions of current.

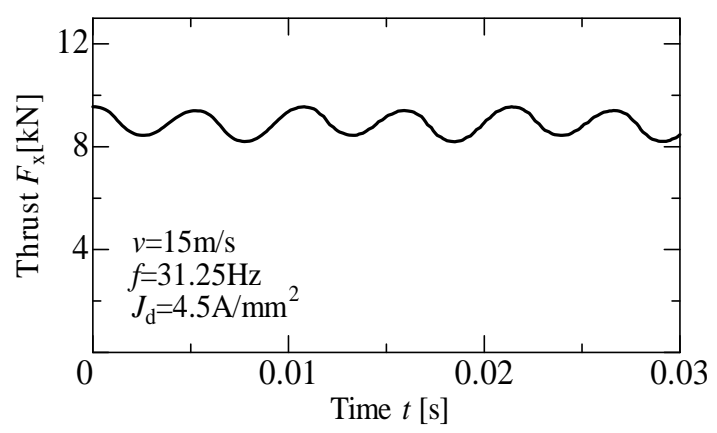

Figure 6. Ripple of thrust in running. 
The normal force means the attractive force between the field and the armature. The normal force is very large because of large air-gap flux density, as shown in Figure 7. The normal force decreases slightly as armature mmf increases. This means that the influence of armature mmf is small. Figure 8 shows the ripple of normal force. The ripple rate is within $\pm 2.3 \%$. This large attractive normal force will be able to use as a force to reduce the vehicle weight by the method like that using in M-BAHN [5].

\subsection{Voltage and Current}

Figure 9 shows the phase voltage of armature winding as functions of armature mmf. The increase with $\mathrm{mmf}$ is small, that is, the characteristics also mean that the influence of armature mmf on the air-gap flux density is small.

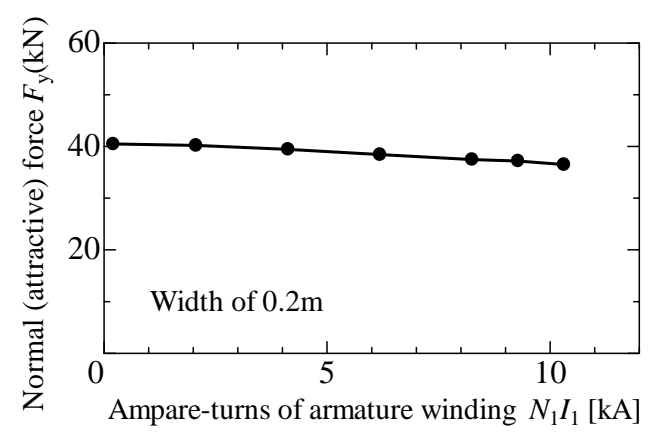

Figure 7. Normal force curve as functions of current.

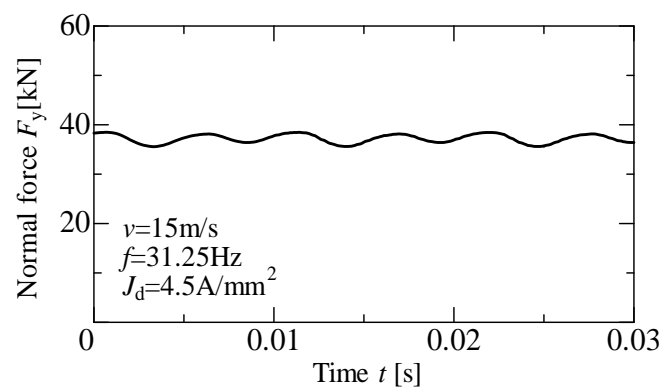

Figure 8. Ripple of normal force in running.

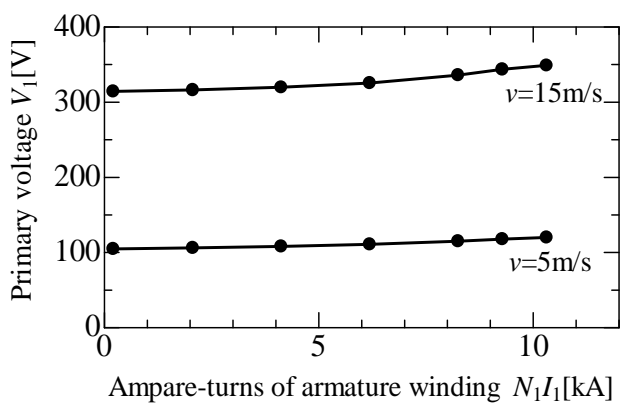

Figure 9. Phase voltage curves as functions of current.
Figure 10 shows the wave form of current when the sinusoidal wave voltage is supplied. The phase difference between voltage and current is small.

\subsection{Power Factor and Efficiency}

The power factor and the efficiency versus thrust vary with a drive control method. The maximum thrust control for given current is adopted here. The power factor $\cos \phi$ shown in Figure 11 is calculated as the following, as the wave form of voltage is not sinusoidal for sinusoidal current.

$$
\cos \phi=\frac{\frac{1}{2 \pi} \int_{0}^{2 \pi} v(t) i(t) d \omega t}{I_{R M S} \sqrt{\frac{1}{2 \pi} \int_{0}^{2 \pi} v^{2}(t) d \omega t}}
$$

where $I_{R M S}$ means the root-mean-square value of current. That is, the power factor is included the influence of distortion of wave form. On the power factor of LSM, the variation by speed or frequency is small. Although the value decreases rapidly as the thrust increases, the overall value is high. The thrust of LSM corresponding to the thrust density of normal rotational motor of $20 \mathrm{kN} / \mathrm{m}^{2}$ $40 \mathrm{kN} / \mathrm{m}^{2}$ is $1.92 \mathrm{kN}-3.84 \mathrm{kN}$. For the region of thrust, the power factor is over 0.98 on this two-dimensional analysis neglecting the inductance of coil end.

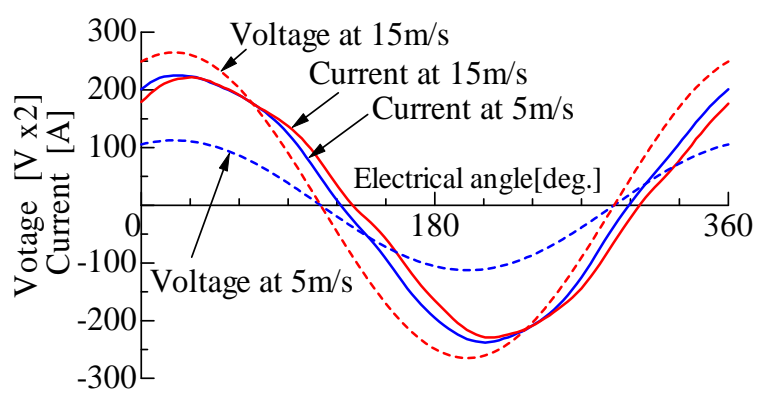

Figure 10. Wave forms of phase voltage and current.

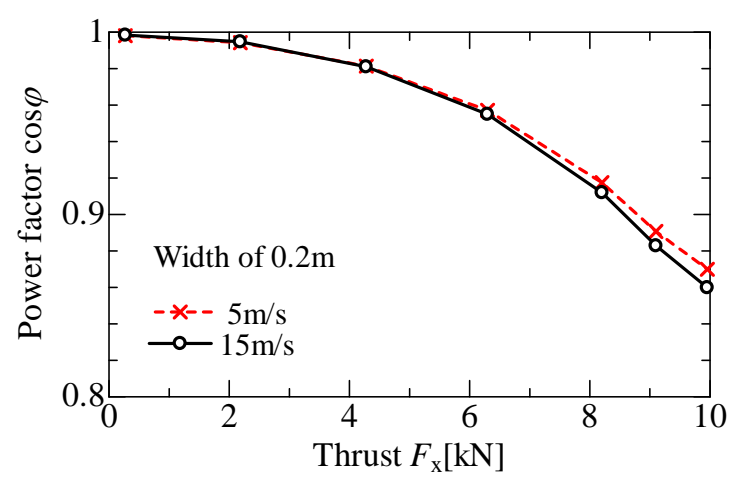

Figure 11. Power factor curve as functions of thrust. 


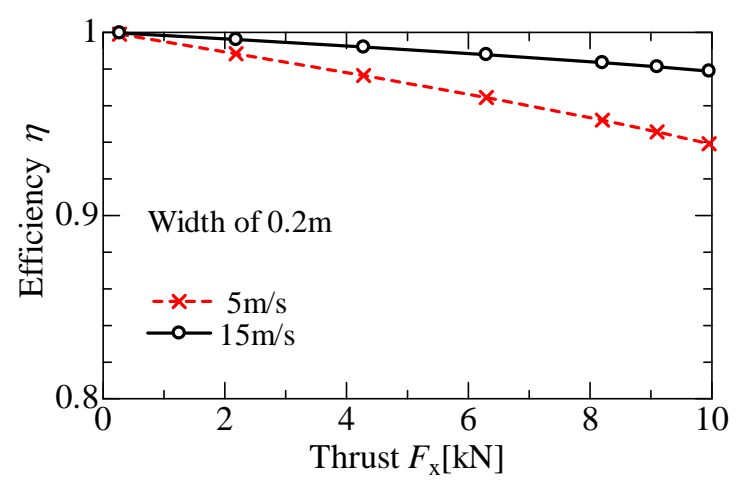

Figure 12. Efficiency curve as functions of thrust.

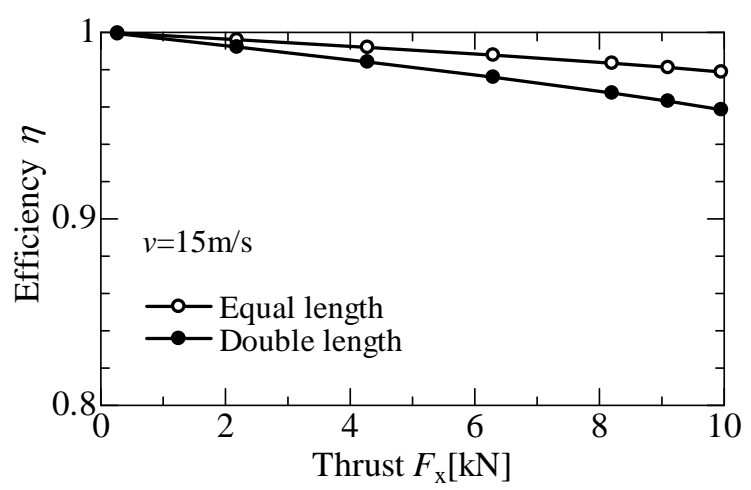

Figure 13. Efficiency for section length of power supply.

Figure 12 shows the efficiency, in which the only ohmic loss of armature winding is considered and the iron loss in both cores is neglected. Even in the low speed of $5 \mathrm{~m} / \mathrm{s}$, the efficiency is over 0.94 .

In a ground primary type of LSM, the switching of armature winding on the guide way is needed. In Figure 12, the length of armature is assumed to be equal to that of field. The double length in Figure 13 means that the supplied section length is twice as long as that of field. The resistance of winding is estimated on the three-dimensional model. The efficiency of this LSM is very high which breaks a conventional belief in the linear motor. In practical application of transportation, this
LSM will can operate at normal thrust density of 20 $\mathrm{kN} / \mathrm{m}^{2}-40 \mathrm{kN} / \mathrm{m}^{2}$, that is $1.92 \mathrm{kN}-3.84 \mathrm{kN}$ of the LSM, meeting the demanded thrust easily.

\section{Conclusions}

1) The simple structure of field of synchronous motor to obtain high air-gap flux density even in a motor with large air-gap is shown.

2) The air-gap flux density beyond the remanent magnetic flux density of rare earth PM is realized easily.

3) For high air-gap flux density and small armature reaction, the very high thrust density beyond the conventional maximum value of $100 \mathrm{kN} / \mathrm{m}^{2}$ can be obtained.

4) In the use in normal thrust density with small mmf of armature, the very high efficiency and power factor are realized, although the results are obtained by simple analysis. This LSM has the potential that the value of efficiency breaks a conventional belief in the linear motor for transportation.

\section{References}

[1] J. F. Gieras and Z. J. Piech, "Linear Synchronous Motors, Transportation and Automation Systems,” CRC Press, 2000.

[2] K. Halbach, "Design of Permanent Multipole Magnets with Oriented Rare Earth Cobalt Material,” Nuclear Instruments and Methods, Vol. 169, 1980, pp.1-10. doi:10.1016/0029-554X(80)90094-4

[3] N. Fujii, T. Mizuma and M. Terata, "Linear Synchronous Motor with High Flux Density,” IEEJ Transmission, Vol. 131-D, No. 3, 2011, pp. 412-413. doi:10.1541/ieejias.131.412

[4] M. Karita, "High Thrust type HD Linear Motor," The Japan Society of Mechanical Engineers, Vol. 101, No. 950, 1998, p. 68.

[5] K. Dreimann, "The M-BAHN Maglev Rapid Transit System-Technology, Status, Experience,” International Conference on MAGLEV AND LINEAR DRIVES, Las Vegas, May 1987, pp. 113-118. 